\title{
Endogenous Neural Stem/Progenitor Cells and Regenerative Responses to Brain Injury
}

\author{
Maria Dizon \\ Northwestern University/Children's Memorial Hospital \\ USA
}

\section{Introduction}

Neural stem and/or progenitor cells (NSPCs) have generated much excitement because of their envisioned potential to treat a variety of central nervous system diseases that span the human lifetime. This chapter is meant as a general introduction to the topic of NSPCs and how they might be thought of in the context of disease, with a particular focus on endogenous NSPCs. My bias is to focus on endogenous NSPCs as an introduction because the transplantation of NSPCs entails its own complex set of problems including, but not limited to, the effects of in vitro culture conditions, problems of delivery to desired anatomical sites and rejection of foreign cells. Endogenous NSPC populations, on the other hand, change with regard to their distribution, rates of proliferation and fate restriction at different points in brain development. Thus, the cells available to respond to disease necessarily differ depending on whether fetal, neonatal, pediatric or adult brain is affected.

Stem cells are defined by their ability to self-renew indefinitely and by their ability to give rise to cells of many phenotypes. True neural stem cells are tripotential and give rise to neurons, oligodendrocytes and astrocytes. Although stem cells, they are restricted in their fate potential as compared, for example, to pluripotent embryonic stem cells that can give rise to an even wider range of cell phenotypes from endoderm, mesoderm and ectoderm. In turn, embryonic stem cells are restricted in their fate potential in comparison to the totipotent cells from a blastocyst. These cells are able to give rise to any cell of an entire organism; indeed they can give rise to the entire organism itself. In contrast, progenitor cells can self-renew, but only for a limited number of generations, and they give rise to cells of limited phenotypes. For example, glial restricted progenitors can give rise only to astrocytes or oligodendrocytes, neuroblasts can give rise only to neurons, and oligodendrocyte progenitor cells can give rise only to oligodendrocytes.

\section{Postnatal neurogenesis and neural stem cells discovered}

Prior to the second half of the twentieth century, the dogma was that neurogenesis did not occur postnatally, much less in adult animals. This idea was based largely on the lack of observed neurons with mitotic figures in adult birds and adult mammals. This stance, firmly taken by the father of neuroscience Dr. Ramon y Cajal, likely led to its endurance for almost 
a century (Ming and Song, 2005). Starting in the 1940s, evidence began to emerge in a number of different species that neurogenesis did indeed occur after development.

\subsection{Earliest evidence is human}

Some of the earliest evidence for the birth of new neurons after development was actually from human studies. It had been known that a mitotically active region from which the cerebral cortex developed, called the subependymal layer, existed embryonically. In studying ependymomas from autopsies, Drs. Globus and Kuhlenheck noted histologic connections and similarities of features between these neoplasms and the subependymal layer of children and adults, and proposed that the tumors had arisen from undifferentiated cells in the subependymal region. This suggested the persistence of what they termed a bipotential mother cell throughout postnatal life. (Globus and Kuhlenheck, 1944).

\subsection{Lower vertebrate evidence}

Starting in the 1950s, it was shown that lower vertebrates, including fish, amphibians and lizards (Zupanc, 2008) could regenerate spinal cord (Anderson and Waxman, 1983), optic nerve (Meyer et al., 1985) and even brain (Zupanc, 1999), (Zupanc and Zupanc, 1992).

\subsection{Rodent evidence}

A breakthrough was made in 1961 when Dr. Smart applied the new technique of labeling dividing cells with tritiated thymidine to 3 day old and adult mice and showed that the subependymal layer of the brain retains its ability to form new cells indefinitely. Standard histologic techniques suggested that these mitotic cells gave rise to neuroblasts and spongioblasts (glial precursors) (Smart, 1961). Shortly thereafter, Dr. Altman began to assemble an impressive body of evidence showing that a large number of interneurons were made postnatally in rat. Like Smart, he used tritiated thymidine, but in contrast he labeled mitotic granule cells within the hippocampus. He showed that these hippocampal granule cells declined from birth with a transient increase at 15 days. Importantly, the decline corresponded with an increase in differentiated granule cells. Later, he extended observations to the olfactory bulb. In both the hippocampus and the olfactory bulb, new interneurons were found continuously at a low rate and were likely born near the ventricles. In contrast, in the cerebellum newly born interneurons were limited to the first three weeks of life. Interneurons were identified both histologically and electrophysiologically. (Altman, 1963; Altman and Das, 1965a; Altman and Das, 1965b; Altman and Das, 1966).

\subsection{Avian evidence}

By the 1980s, Dr. Nottebohm and colleagues had also clearly demonstrated neurogenesis within the brain of adult birds. Again using tritiated thymidine, they showed that a forebrain nucleus of songbirds (the hyperstriatum ventralis pars caudalis $(\mathrm{HVc})$ ), varied greatly in size depending on sex and stage of song development, and that this change in size was related to the birth of new neurons. Cells were identified as neurons ultrastructurally and electrophysiologically. Because labeling was heaviest in the ventricular zone, neurons were presumed to have been born in this zone and to have migrated into the overlying HVc (Goldman and Nottebohm, 1983; Nottebohm, 1985) Interestingly it was Dr. Alvarez-Buylla, 
who had previously worked on songbirds with Dr. Nottebohm, who revisited the subependymal origin of new neurons in rodent olfactory bulb in the 1990s, and more precisely characterized this region (Lois and Alvarez-Buylla, 1993; Lois and Alvarez-Buylla, 1994).

\subsection{Primate evidence}

Unfortunately, despite the accumulating evidence, widely held beliefs predominated. As adult neurogenesis was conceded to vertebrates, and even mammals, scientists continued to hold the view that primates were different. Perhaps related to the sensitivity of tritiated thymidine studies, as late as 1985 Dr. Rakic asserted that neurogenesis was limited to development and early postnatal life in primates (Rakic, 1985). It was not until the late 1990s that this view was debunked by Dr. Gould using the thymidine analogue BrdU in adult macaques to show neurogenesis in the hippocampus (Gould et al., 1999a) and even in the neocortex (association cortex) (Gould et al., 1999b). Existence of adult neurogenesis in humans was finally widely embraced by the scientific community in the late twentieth century when Dr. Gage's group demonstrated neurogenesis in adult human dentate gyrus using tissue from cancer victims who had been treated with BrdU (Eriksson et al., 1998). They also formally studied human neocortex using similarly BrdU-treated cancer victims combined with carbon 14 exposure from Cold War above ground nuclear bomb tests and ruled out neocortical neurogenesis after development (Bhardwaj et al., 2006). Recently, a human rostral migratory stream of neuroblasts from subventricular zone to the olfactory bulb was demonstrated by Dr. Curtis (Curtis et al., 2007).

\subsection{Neurogenesis indicates neural stem cells}

Implicit in the concept of neurogenesis is the existence of a precursor cell capable of giving rise to a neuron. This precursor cell's fate might be limited to neurons, e.g. a restricted neuronal progenitor. Alternatively, the precursor cell might be capable of giving rise to neurons and another cell type such as an oligodendrocyte, e.g. a less restricted bipotential progenitor. Or it might even be capable of giving rise to neurons, oligodendrocytes or astrocytes, e.g. a multipotential neural stem cell. Thus, the firm establishment of postnatal neurogenesis indicates the existence of postnatal neural stem/ progenitor cells (NSPCs).

\section{Regional distribution of NSPCs}

We will discuss the distribution of neural stem cells and more restricted progenitors and how their distribution changes over time. Rodent development is discussed as the bulk of experimental evidence to date derives from rodent studies. Rat brain development has been shown to correlate with mouse brain development. Furthermore, P7 rodent brain development has been shown to correlate with preterm human brain development (Craig et al., 2003). Much insight has been gained from in vitro culture experiments. However, data from in vivo studies including fate mapping experiments using Cre-lox transgenic mouse technology overcomes the uncertainty introduced by culture effects, so the focus here will be on data gleaned from in vivo work. The overarching theme is that earlier in development, precursors tend to be multipotential but become more restricted with time. 


\subsection{Embryonic period}

\subsubsection{Early embryonic period}

During embryogenesis, the open neural plate folds to form the neural tube. As a result, the primary germinal matrix or neuroepithelium comes to line the lumen that will become the ventricles. Initially, the primary neuroepithelium is a simple columnar epithelium composed of so-called radial glial cells that span from the ventricle to the pial surface. Radial glial cells are more than just glia but are, in fact, "mother cells." They divide after interkinetic nuclear migration from basal surface to the pial surface and back again. Internuclear kinetic migration gives the appearance of a pseudo-stratified epithelium (Altman and Bayer, 1991; Altman and Bayer, 2011). Radial glia divide either symmetrically to form two identical cells, or asymmetrically to give rise to one stem cell and one neuroblast. The neuroblast, using the radial glia's process as a guide, migrates radially toward the pial surface and differentiates into a projection neuron after reaching its destination (Rakic, 1971; Malatesta et al., 2000; Noctor et al., 2001). At E13 the primary neuroepithelium can be subdivided into a more compact zone adjacent to the ventricle called the ventricular zone (VZ), a less cell-dense area more distant from the ventricle called the mantle, and a cell poor area most distant from the ventricle called the marginal zone (Globus and Kuhlenheck, 1944; Altman, 2011). Generally, later migrating neuroblasts move past previously migrated neuroblasts, thus forming the six cortical layers in an inside-out fashion (although Layer I lies closest to the pial surface) (Altman and Bayer, 1991; Altman and Bayer, 2011). During the early embryonic period, the VZ is the most important source of NSPCs and gives rise to projection neurons. The VZ also is the source of cells that create the subsequent germinal matrices.

\subsubsection{Mid-late embryonic period}

The secondary germinal matrix, termed the subventricular zone (SVZ), begins to evolve as the lateral ganglionic eminence and medial ganglionic eminence enlarge between E12 and E14 as a result of mitotic cells contributed by the VZ, adjacent to it but more distant from the ventricle. NSPCs continue to expand within the SVZ creating a truly stratified epithelium that differs from the VZ. Here the NSPCs do not undergo interkinetic nuclear migration. Nor are the cleavage planes of the mitotic cells oriented in any particular way with regard to the ventricle, so the SVZ does not fit neatly within the symmetrical v. asymmetrical explanation for expansion of NSPCs (Altman and Bayer, 1991; Altman and Bayer, 2011). SVZ NSPCs are tripotential.

During mid-gestation, the SVZ gives rise to neuroblasts that migrate radially to the cortex where they differentiate into interneurons (Altman and Bayer, 2011). The SVZ also gives rise to some OPCs that migrate to the striatum, subcortical white matter and neocortex (Levison and Goldman, 1997; Suzuki and Goldman, 2003) where they persist as oligodendroglial progenitors (OPCs) or differentiate into mature oligodendrocytes (Dawson et al., 2003). Simultaneously the VZ is also a source of OPCs. Distinct populations of VZ NSPCs contribute OPCs at different timepoints in development. Between E11.5 and E14.5, Nkx2.1expressing NSPCs in the ventral VZ overlying the medial ganglionic eminence and the anterior entopeduncular area give rise to OPCs that migrate radially to the cortex. Later by E16.5, Gsh-2-expressing NSPCs from VZ overlying the lateral ganglionic eminence and caudal ganglionic eminence give rise to OPCs that migrate radially to the cortex (Kessaris et al., 2006). 
Starting at approximately E14, radial glial cells start to gradually transform into astrocytes. Nonetheless, the VZ peaks in size at E17 and decreases in size between E18 to E21. Thus the VZ transiently coexists with the SVZ (Temple, 2001).

A tertiary germinal matrix can be found in the hippocampus at E16. Starting at E14.5, NSPCs proliferate at the dentate notch, then differentiate into neuroblasts that migrate along radial glia before differentiating further into granule cell neurons to form the blades of the dentate gyrus. Subsequently, more neuroblasts migrate along the same path but accumulate as mitotic progenitors to form the hilus of the dentate gyrus. Thus, the dentate gyrus is essentially a specialized subventricular zone. The true tertiary germinal matrix is the border between the granule cell layer and the hilus, also known as the subgranular zone (SGZ) (Li and Pleasure, 2005). NSPCs residing at the SGZ give rise to granule cell neurons (Ray et al., 1993).

The SVZ is fully formed by E15-16, and becomes larger than the VZ by E18. The peak of neurogenesis takes place between E14-E17 with the VZ and the SVZ both contributing neurons at this time. Thus, during mid gestation, both the VZ and SVZ are important sources of NSPCs that generate projection neurons and interneurons respectively. By late embryonic life NSPCs are restricted to the SVZ and the SGZ and their fate is further restricted to either a glial or a neuronal fate in the SVZ and a neuronal fate in the SGZ. By late gestation, the SVZ becomes the most important source of NSPCs capable of generating interneurons and oligodendrocytes.

\subsection{Postnatal period}

At the time of birth, cortical neurogenesis has ended. The VZ no longer exists and has been replaced by the ependyma. The SVZ and SGZ persists postnatally throughout childhood into adulthood. Evidence shows an SVZ containing NSPCs exists in adult humans as well.

\subsubsection{Early postnatal period}

Postnatally, neurogenesis is confined to the olfactory system and the hippocampus. SVZ neuroblasts no longer migrate radially, but have changed direction and now migrate tangentially through the rostral migratory stream to the olfactory bulb where they differentiate into interneurons (Marshall et al., 2003). By P10, the SGZ is well established and NSPCs here continue to give rise to hippocampal granule cell neurons ( $\mathrm{Li}$ and Pleasure, 2005).

Oligodendrogenesis, on the other hand, continues to be widespread during the first postnatal week and their source is diverse. At birth, Nkx2.1-derived OPCs are abundant in the cortex. Postnatally, Emx1-expressing NSPCs located dorsally in the cortex give rise to OPCs that populate the corpus callosum and cortex. By P10, the majority of OPCs and oligodendrocytes derive from Emx-1- and Gsh-2-expressing NSPCs, but very few OPCs derive from Nkx2.1-expressing NSPCs remain (Kessaris et al., 2006). As well, OPCs migrate from the SVZ to the striatum, white matter and medial, dorsal and lateral regions of the cortex where they reside as progenitors or differentiate into mature oligodendrocytes. A small proportion the OPCs in the corpus callosum comes from the SVZ (Rivers, 2008). This wave of migration ends by P14.

Also around the time of birth a distinct population of cells migrates from the SVZ to striatum, white matter and medial, dorsal and lateral regions of the cortex to form astrocytes. 
In summary, the bulk of neurogenesis occurs prenatally while the bulk of oligodendrogenesis occurs postnatally with a peak in mouse between P7-P14 (Wright et al., 2010). As in late gestation, in the postnatal period the SVZ remains the most important source of NSPCs for the generation of olfactory interneurons and oligodendrocytes throughout the brain. The SGZ remains an important source of NSPCs for the generation of granule cell neurons within the hippocampus.

\subsubsection{Adult period}

Neurogenesis during adulthood is confined to the olfactory system and the hippocampus. As mentioned above, some of the OPCs that migrated in the late embryonic period and early postnatal period persist within the striatum, white matter and cortex as progenitors (Dawson et al., 2003). Thus, OPCs are found throughout the adult brain. OPCs are characterized by expression of markers including Olig2, PDGFRA and NG2. It is controversial whether NG2+/PDGFRA+ cells scattered throughout the neocortex are truly restricted oligodendrocyte progenitors. Recently, NG2 cells were shown to have characteristics of NSPCs, giving rise to both gray and white matter. In fact, there is some evidence that they are tripotential. This issue has been explored in vivo using Cre conditional mutants and Cre conditional inducible mutants. Using the NG2CreBAC:Z/EG mouse, Zhu et al., showed that EGFP+ cells residing in white matter give rise to OL, whereas those residing in gray matter give rise to OL and some astrocytes (Zhu et al., 2008). As NG2+ cells in adult mice co-express PDGFRA and vice versa, Rivers et al., showed using the PDGFRACreERT2;Rosa26-YFP mouse, that cells that had expressed PDGFRA and their progeny give rise to myelinating oligodendrocytes in the corpus callosum and to projection neurons in the piriform cortex but never astrocytes (Rivers et al., 2008). As NG2+ cells also express Olig2 and vice versa, Dimou et al, showed using the Olig2CreER mouse, that cells that had expressed Olig2 and their progeny give rise to myelinating oligodendrocytes in white matter but not gray matter and became post-mitotic in gray matter, suggesting a non-progenitor function in these regions (Dimou et al., 2008). Interestingly, both ventrally derived (Gsh2-derived) and dorsally derived (Emx1-derived) precursors contribute equally to dividing and non-dividing subpopulations of NG2 cells (Psachoulia, 2009). The conclusion is that the overwhelming progeny of NG2 cells are oligodendrocytes but much less often are astrocytes and neurons. NG2 cells may be a class of cells with a unique function in their own right.

\begin{tabular}{|l|l|l|}
\hline Developmental Period & Location & Differentiated Progeny Phenotype \\
\hline Early Embryonic & VZ & Projection Neurons, OPCs \\
\hline Mid-Late Embryonic & VZ, SVZ, SGZ & $\begin{array}{l}\text { Projection Neurons, OPCs/NG2 } \\
\text { cells, Cortical Interneurons, } \\
\text { Hippocampal Granule Cell } \\
\text { Neurons, Oligodendrocytes }\end{array}$ \\
\hline Postnatal & $\begin{array}{l}\text { SVZ, SGZ, striatum, corpus } \\
\text { callosum, cortex }\end{array}$ & $\begin{array}{l}\text { Olfactory Cortical Interneurons, } \\
\text { Hippocampal Granule Cell } \\
\text { Neurons, OPCs/NG2 cells, } \\
\text { Oligodendrocytes }\end{array}$ \\
\hline Adulthood & $\begin{array}{l}\text { SVZ, SGZ, striatum, corpus } \\
\text { callosum, cortex } \\
\text { Hippocampal Granule Cell } \\
\text { Neurons, OPCs/NG2 cells, } \\
\text { Oligodendrocytes }\end{array}$ \\
\hline
\end{tabular}

Table 1. Distribution and progeny of NSPCs during development. 
In adulthood, the SVZ remains an important source of NSPCs for the generation of olfactory interneurons and the SGZ remains an important source of NSPCs for the generation of granule cell neurons. In addition, widely spread throughout the brain are NG2 cells that are accepted as OPCs but may also be source NSPCs for projection neurons in the piriform cortex and for gray matter astrocytes.

\begin{tabular}{|l|l|}
\hline Precursor Cell Phenotype & Markers \\
\hline Neural stem cells & Nestin, GFAP, Sox2 \\
\hline Neuroblasts & Dcx \\
\hline Oligodendrocyte Progenitor Cells & Olig2, NG2, PDGFRA, Sox10 \\
\hline
\end{tabular}

Table 2. Markers of neural stem cells and restricted progenitors.

\section{NSPCs in perinatal hypoxia-ischemia}

Despite the restricted fate for progenitors in development, it seems that injury can provoke a relaxation of this fate restriction. We will review how SVZ cells respond to perinatal hypoxia-ischemia in terms of proliferation, fate commitment and migration. The response of NSPCs to stroke is covered elsewhere in this book.

In vitro data suggest that the SVZ responds to perinatal hypoxia-ischemia by attempting to regenerate lost cells through increased proliferation and also a shift in fate potential. Neurospheres generated from the SVZ of neonatal rats subjected to hypoxia-ischemia yield oligodendrocytes more often than neurospheres generated from non-lesioned rats (Felling et al., 2006; Yang and Levison, 2006). In vivo data also support a regenerative response by the SVZ that includes increased emigration as well. Plane et al. showed an increase in neuroblasts (BrdU+/Doublecortin+ cells) in SVZ and striatum 2 weeks after perinatal hypoxia-ischemia in the mouse, however no mature neurons (BrdU+/NeuN+ cells) 3 weeks after injury (Plane et al., 2004). Similarly in rat, Ong et al. showed an increase in SVZ neuroblasts (BrdU+/Doublecortin+ cells) 2-3 weeks after perinatal hypoxia-ischemia but no increase in mature neurons (BrdU+/NeuN+ cells) in striatum 4 weeks after injury (Ong et al., 2005). By contrast, Yang and Levison did show an increase in neuroblasts (BrdU+/Doublecortin+ cells) and mature neurons (BrdU+/NeuN+ cells) up to 5 months after perinatal hypoxia-ischemia in the rat. They also marked SVZ cells with Retroviral-AP and showed that these newly born neuroblasts and mature neurons originated from the SVZ (Yang and Levison, 2007). Several groups have shown that, 4 weeks after perinatal hypoxicischemic injury, newly born oligodendrocytes (BrdU+/MBP+ cells, BrdU+/carbonic anhydrase+ cells, and BrdU+/RIP+ cells) are found in the striatum, corpus callosum and infarcted cortex (Back et al., 2002; Zaidi et al., 2004; Ong et al, 2005).

By contrast our work, focusing on the oligodendroglial lineage, did not show an increase in emigration of OPCs from SVZ after perinatal hypoxia-ischemia. Like others, we showed an increase in neural progenitors in SVZ in response to perinatal HI; specifically, we showed an increase in OPCs in vivo (Figure 1) (Dizon et al., 2010).

Given that OPCs are actively migrating during the timing of perinatal hypoxic-ischemic injury, we expected to see an increase in OPC migration. Rather, using multi-photon microscopy to image OPCs in slice cultures derived from lesioned Olig1-EGFP mice, we showed a paucity of OPC emigration from SVZ. Nonetheless, we showed an increase of Olig1-EGFP+ cells within cortex and striatum in response to perinatal HI (Figure 2) (Dizon et al., 2010). 
Control

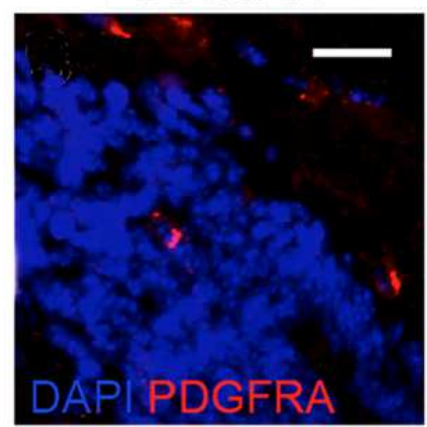

Lesion

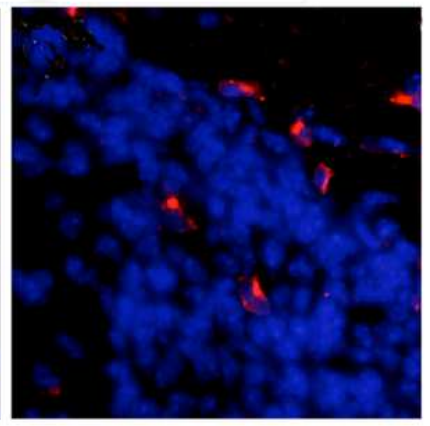

Fig. 1. Perinatal hypoxia-ischemia causes an increase in OPCs marked by PDGFRA within the SVZ by 7 days post lesion $(\mathrm{dpl})$. Scale bar $=50$ microns. ${ }^{*} \mathrm{p}=0.013$.

Control

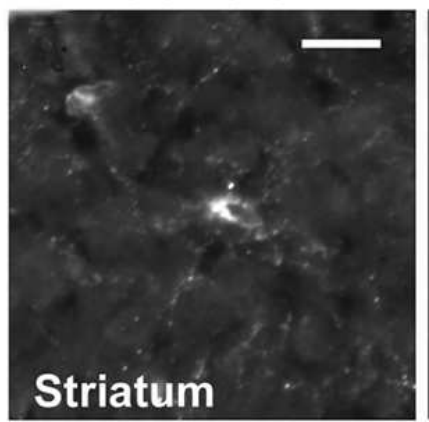

Lesion

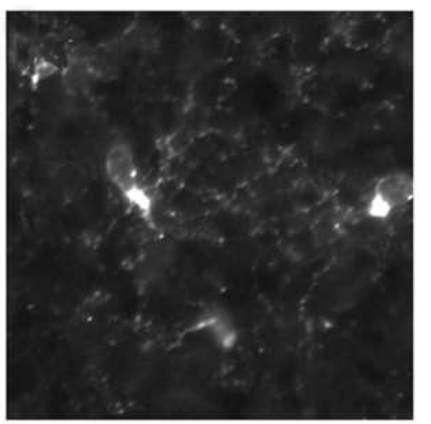

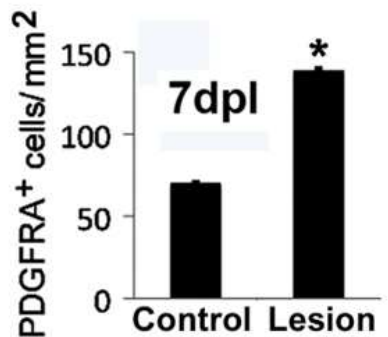

Fig. 2. Perinatal hypoxia-ischemia causes an increase in OPCs marked by PDGFRA within the striatum by 7 days post lesion $(\mathrm{dpl})$. Scale bar $=50$ microns. ${ }^{*} \mathrm{p}=0.003$.

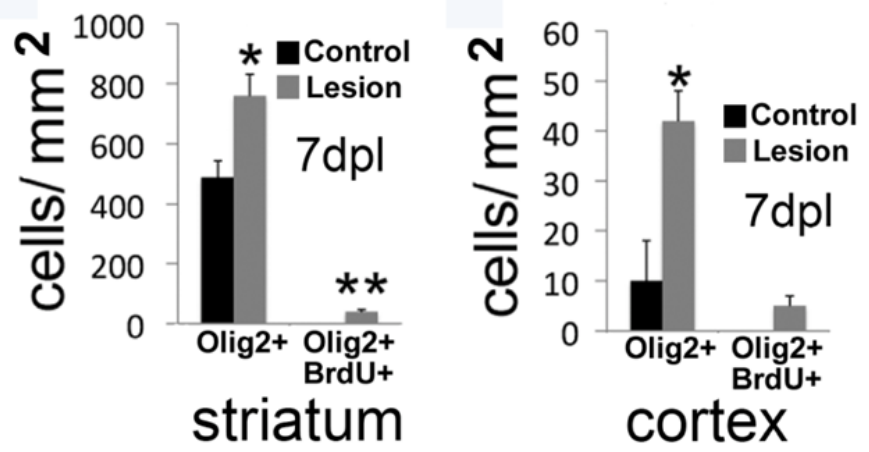

Fig. 3. Increases in OPCs marked by Olig2 result from increased proliferation of OPCs in the striatum but not in the cortex as evidenced by doublemarking with BrdU. Striatum: ${ }^{*} \mathrm{p}=0.044,{ }^{* *} \mathrm{p}=0.031$. Cortex: ${ }^{*} \mathrm{p}=0.037$. 
We also found an increase in OPCs within the cortex. Interestingly, by marking newly born cells with BrdU, we showed that increased OPCs in the striatum arise through proliferation but this is not true for the cortex (Figure 3).

Therefore, we speculated that increased OPCs may arise via increased fate commitment of uncommitted neural progenitors. Thus, we have turned our attention to local neural progenitors and strategies to augment endogenous regenerative responses to white matter injury, specifically toward manipulation of regulators of NSPC fate, namely bone morphogenetic proteins (BMPs). BMPs negatively regulate an oligodendroglial fate choice by NSPCs. Recently, using a transgenic mouse that overexpresses the BMP antagonist noggin during the period of oligodendrogliogenesis, we were able to obtain increased OPCs and myelinating oligodendrocytes as well as improved motor function in lesioned noggin overexpressing mice compared to lesioned wildtype mice (Dizon et al., 2011). Subsequently, another group has independently shown improved outcomes in a rabbit model of perinatal hypoxia-ischemia when pups were treated with recombinant noggin protein after injury (Dummula et al., 2011). We are currently targeting BMP receptor subunits to more precisely downregulate signaling in in vivo experiments utilizing conditional inducible ablation of BMP receptor subunits BMPR1a, BMPR1b and BMPR2 following injury. We would anticipate that our strategies, if successful, could be applied to other diseases of white matter at other developmental timepoints including congenital dysmyelination and multiple sclerosis.

In conclusion, the abundance and fate restriction of available neural precursors to address disease states varies depending on the time during development. Nonetheless, manipulation of endogenous progenitors may be a more promising therapy than transplanted progenitors as there is no need to overcome problems with rejection.

\section{Conclusions}

In conclusion, the endogenous NSPC cell populations capable of replacing cells lost to disease are specific to the period of development during which injury is sustained as well as to the location of injury. Unlike NSPCs from SVZ or SGZ, NSPCs of the NG2 type are not restricted to these regions but reside in the many brain regions that may be injured throughout the lifetime. Thus, NG2 cells likely reside more proximal to injured regions and might more readily respond, so they may be the more appropriate target for research efforts rather than SVZ cells. In addition, more specific groups of NG2 cells might be targeted. For example, Emx1-derived NSPCs might give rise to OPCs that are capable of compensating for lost white matter in an adult animal, while Nkx2.1-derived NSPCs would more appropriately be targeted to regenerate white matter in newborns; these cells would not be present so could not be exploited in adult onset diseases. Rational therapy would target restricted population of NSPCs, thereby confining therapies to the cells best able to effect regeneration while also minimizing unwanted side effects.

\section{References}

Altman, J. (1963). Autoradiographic investigation of cell proliferation in the brains of rats and cats. Anatomical Record. 145, 573-91.

Altman, J., Das, G. D. (1965a). Autoradiographic and histological evidence of postnatal hippocampal neurogenesis in rats. Journal of Comparative Neurolology. 124, 319-35. 
Altman, J., Das, G. D. (1965b). Post-natal origin of microneurones in the rat brain. Nature. 207, 953-6.

Altman, J., Das, G. D. (1966). Autoradiographic and histological studies of postnatal neurogenesis. I. A longitudinal investigation of the kinetics, migration and transformation of cells incorporating tritiated thymidine in neonate rats, with special reference to postnatal neurogenesis in some brain regions. Journal of Comparative Neurology. 126, 337-89.

Anderson, M. J., Waxman, S. G. (1983). Caudal spinal cord of the teleost Sternarchus albifrons resembles regenerating cord. Anatomical Record. 205, 85-92.

Bayer, S.A., and Altman, J. (1991). Neocortical Development, Raven Press, Retrieved from: <http://neurondevelopment.org>

Bayer, S.A., and Altman, J. (2011a) Laboratory Memoir, In: Neuron Development, Available from: <http://neurondevelopment.org>

Back, S.A., Han B.H., Luo, N.L., Chricton, C.A. Zanthoudakis, S., Tam, J. , Arvin, K.L., Holtzman, D.M. (2002). Selective vulnerabiliry of late oligodendrocyte progenitors to hypoxia-ischemia. Journal of Neuroscience. 22: 455-463.

Bhardwaj, R. D., Curtis, M.A., Spalding, K.L., Buchholz, B.A,, Fink, D., Bjork-Erikkson, T., Nordborg, C., Gage, F.H., Druid, H., Erikkson, P.S., Frisen, J.. (2006). Neocortical neurogenesis in humans is restricted to development. Proceedings of the National Academy of Science U S A. 103, 12564-8.

Craig, A., Ling, L.N., Beardsley, D.J., Wingate-Pearse, N., Walker, D.W., Hohimer, A.R., Back, S.A. (2003). Quantitative analysis of perinatal rodent oligodendrocyte lineage progression and its correlation with human. Experimental Neurology. 181, 231-40.

Curtis, M. A., Kam, M., Nannmark, U., Anderson, M.F., Axell, M.Z., Wikkelso, C., Holtas, S., van Roon-Mom, W.M., Bjork-Eriksson, T., Nordberg, C., Fresn, J., Dragunow, M., Faull, R.L., Eriksson, P.S. (2007). Human neuroblasts migrate to the olfactory bulb via a lateral ventricular extension. Science. 315, 1243-9.

Dawson., M.R., Polito, A., Levine, J.M., Reynolds, R. (2003). NG2-expressing glial progenitors cells: an abundant and widespread population of cycling cells in the adult rat CNS. Molecular and Cellular Neuroscience. 24:476-488.

Dimou, L., Simon, C., Kirchoff, F., Takebayashi, H., Gotz, M. (2008). Progeny of Olig2expressing progenitors in gray and white matter of the adult mouse cerebral cortex. Journal of Neuroscience. 28, 10434-42.

Dizon, M., Szele, F., Kessler, J.A. (2010). Hypoxia-ischemia induces an endogenous reparative response by local neural progenitors in the postnatal mouse telencephalon. Developmental Neuroscience. 32, 173-83.

Dizon, M.L., Maa, T., Kessler, J.A. (2011).The bone morphogenetic protein antagonist noggin protects white matter after perinatal hypoxia-ischemia. Neurobiology of Disease. 42, 318.26.

Dummula, K., Vinukonda, G., Chu, P., Xing, Y., Hu, F., Mailk, S., Csiszar, A., Chua, C., Mouton, P., Kayton, R.J., Brumberg, J.C., Bansal, R., Ballabh, P. (2011). Bone morphogenetic protein inhibition promotes neurological recovery after intraventricular hemorrhage. Journal of Neuroscience. 31:12068-12082.

Eriksson, P. S., Perfilieva, E., Bjork-Eriksson, T., Alborn, A.M., Nordborg, C., Peterson, D.A., Gage, F.H. (1998). Neurogenesis in the adult human hippocampus. Nature Medicine. 4, 1313-7. 
Felling, R.J., Snyder, M.J., Romanko, M.J., Rothstein R.P., Zeigler, A.N., Yang, Z. Givogri, M.I., Bongarzone, E.R., Levison, S.W. (2006). Neural stem/progenitor cells participate in the regenerative response to perinatal hypoxia/ischemia. Journal of Neuroscience. 26, 4359-4369.

Globus, J.H., Kuhlenbeck, H. (1944). The subependymal cell plate (matrix) and its relationship to brain tumors of the ependymal type. Journal of Neuropathology and Experimental Neurology. 3:1-35.

Goldman, S. A., Nottebohm, F. (1983). Neuronal production, migration, and differentiation in a vocal control nucleus of the adult female canary brain. Proceedings of the National Academy of Sciences U S A. 80, 2390-4.

Gould, E., Reeves, A.J., Fallah, M., Tanapat, P., Gross, C.G., Fuchs, E. (1999a). Hippocampal neurogenesis in adult Old World primates. Proceedings of the National Academy of Sciences U S A. 96, 5263-7.

Gould, E., Reeves, A.J., Graziano, M.S., Gross, C.G. (1999b). Neurogenesis in the neocortex of adult primates. Science. 286, 548-52.

Kessaris, N., Fogarty, M., Iannarelli, P., Grist, M., Wegner, M., Richardson, W.D. (2006). Competing waves of oligodendrocytes in the forebrain and postnatal elimination of an embryonic lineage. Nature Neuroscience. 9, 173-179.

Levison, S.W. and Goldman, J.E. (1997). Multipotential and lineage restricted precursors coexist in the mammalian perinatal subventricular zone. Journal of Neuroscience Research. 48, 83-94.

Li, G., and Pleasure, S.J. (2005). Morphogenesis of the dentate gyrus: what we are learning from mouse mutants. Developmental Neuroscience. 27:93-99.

Lois, C., Alvarez-Buylla, A. (1993). Proliferating subventricular zone cells in the adult mammalian forebrain can differentiate into neurons and glia. Proceedings of the National Academy of Sciences U S A. 90, 2074-7.

Lois, C., Alvarez-Buylla, A. (1994). Long-distance neuronal migration in the adult mammalian brain. Science. 264, 1145-8.

Malatesta, P., Hartfuss, E., Gotz, M. (2000) Isolation of radial glial cells by fluorescentactivated cell sorting reveals a neuronal lineage. Development. 127:5253-63.

Marshall, C. A., et al., (2003). Gliogenic and neurogenic progenitors of the subventricular zone: who are they, where did they come from, and where are they going? Glia. 43, 52-61.

Menn, B., Garcia-Verdugo, J.M., Yaschine, C., Gonzalez-Perez, O., Rowtich, D., AlvarezBuylla, A. (2006). Origin of oligodendrocytes in the subventricular zone of the adult brain. Journal of Neuroscience. 26, 7907-7918.

Meyer, R. L., et al., (1985). Topography of regenerating optic fibers in goldfish traced with local wheat germ injections into retina: evidence for discontinuous microtopography in the retinotectal projection. Journal of Comparative Neurology. $239,27-43$.

Ming, G. L.and Song, H. (2005). Adult neurogenesis in the mammalian central nervous system. Annual Reviews of Neuroscience. 28, 223-50.

Noctor, S.C., Flint, A.C., Weissman, T.A., Dammerman, R.S., Kriegstein, A.R. (2001). Neurons derived from radial glial cells establish radial units in neocortex. Nature. 409, 714-720.

Nottebohm, F. (1985). Neuronal replacement in adulthood. Annals of the New York Academy of Sciences. 457, 143-61. 
Ong, J., Plane, J.M., Parent, J.M., Silverstein, F.S. (2005). Hypoxic-ischemic injury stimulates subventricular zone proliferation and neurogenesis in the neonatal rat. Pediatric Research. 58:600-606.

Plane, J.M., Liu, R., Wang, T.W., Silverstein, F.S., Parent, J.M. (2004). Neonatal hypoxicischemic injury increases forebrain subventricular zone neurogenesis in the mouse. Neurobiology of Disease 16:585-595.

Psachoulia, K., Jamen, F., Young, K.M., Richardson, W.D. (2009). Cell cycle dynamics of NG2 cells in the postnatal and ageing brain. Neuron Glia Biology. 5, 57-67.

Ray, J., Peterson, D.A., Schinstine M., Gage, F.H.(1993). Proliferation, differentiation, and long term culture of primary hippocampal neurons. Proceedings of the National Academy of Sciences. 90:3602-6.

Rakic, P. (1971). Guidance of neurons migrating to the fetal monkey neocortex. Brain Research. 33, 471-476.

Rakic, P. (1985). Limits of neurogenesis in primates. Science. 227, 1054-6.

Rivers, L.E., Young, K.M., Rizzi, M., Jamen, F., Psachoulia, K., Wade, A., Kessaris, N., Richardson, W.D. (2008). PDGFRA/NG2 glia generate myleinating oligodendrocytes and piriform projection neurons in adult mice. Nature Neuroscience. 11: 1392-401.

Smart, I., (1961). The subependymal layer of the mouse brain and its cell production as shown by autography after $\left[\mathrm{H}^{3}\right\}$-thymidine injection. Journal of Comparative Neurology. 116:325-27.

Suzuki, S.O., and Goldman, J.E. (2003). Multiple cell populations in the early postnatal subventricular zone take distinct migratory pathways: a dynamic study of glial and neuronal progenitor migration. Journal of Neuroscience. 23. 4240-4250.

Wright, J. Zhang, G., Yu, T.S., Kernie, S.G. (2010). Age related changes in the oligodendrocyte progenitor pool influence brain remodeling after injury. Developmental Neuroscience. 32:499-509.

Yang, Z., and Levison, S.W. (2006). Hypoxia/ischemia expands the regenerative capacity of progenitors in the perinatal subventricular zone. Neuroscience. 139:555-64.

Yang, Z., and Levison, S.W. (2007). Perinatal hyposic-ischemic brain injury induces persistent production of striatal neurons from subventricular zone progenitors. Developmental Neuroscience. 29:331-340.

Zaidi, A.U., Bessert, D.A., Ong, J.E., Xu, H., Barks, J.D., Silverstein, F.S., Skoff, R.P. (2004). New oligodendrocytes are generated after neonatal hypoxic-ischemic brain injury in rodents. Glia. 46:380-390.

Zhu, X., Bergles, D.E., Nishiyama, A. (2008). Ng2 cells generate oligodendrocytes and gray matter astrocytes. Development. 135:145-157.

Zupanc, G. K. (1999). Neurogenesis, cell death and regeneration in the adult gymnotiform brain. Journal of Experimental Biology. 202, 1435-46.

Zupanc, G. K. (2008). Adult neurogenesis and neuronal regeneration in the brain of teleost fish. Journal of Physiology Paris. 102, 357-73. 


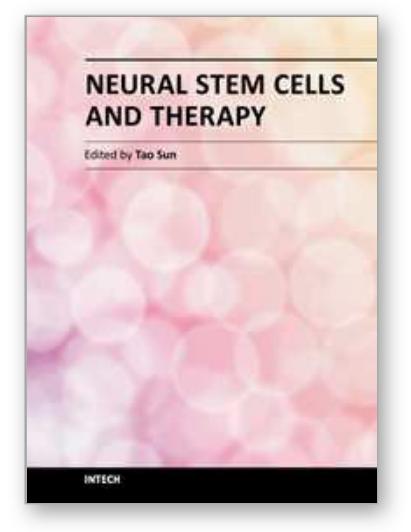

\author{
Neural Stem Cells and Therapy \\ Edited by Dr. Tao Sun
}

ISBN 978-953-307-958-5

Hard cover, 440 pages

Publisher InTech

Published online 15, February, 2012

Published in print edition February, 2012

This book is a collective work of international experts in the neural stem cell field. The book incorporates the characterization of embryonic and adult neural stem cells in both invertebrates and vertebrates. It highlights the history and the most advanced discoveries in neural stem cells, and summarizes the mechanisms of neural stem cell development. In particular, this book provides strategies and discusses the challenges of utilizing neural stem cells for therapy of neurological disorders and brain and spinal cord injuries. It is suitable for general readers, students, doctors and researchers who are interested in understanding the principles of and new discoveries in neural stem cells and therapy.

\title{
How to reference
}

In order to correctly reference this scholarly work, feel free to copy and paste the following:

Maria Dizon (2012). Endogenous Neural Stem/Progenitor Cells and Regenerative Responses to Brain Injury, Neural Stem Cells and Therapy, Dr. Tao Sun (Ed.), ISBN: 978-953-307-958-5, InTech, Available from: http://www.intechopen.com/books/neural-stem-cells-and-therapy/endogenous-neural-stem-progenitor-cellsand-regenerative-responses-to-brain-injury

\section{INTECH}

open science | open minds

\section{InTech Europe}

University Campus STeP Ri

Slavka Krautzeka 83/A

51000 Rijeka, Croatia

Phone: +385 (51) 770447

Fax: +385 (51) 686166

www.intechopen.com

\section{InTech China}

Unit 405, Office Block, Hotel Equatorial Shanghai

No.65, Yan An Road (West), Shanghai, 200040, China

中国上海市延安西路65号上海国际贵都大饭店办公楼405单元

Phone: +86-21-62489820

Fax: $+86-21-62489821$ 
(C) 2012 The Author(s). Licensee IntechOpen. This is an open access article distributed under the terms of the Creative Commons Attribution 3.0 License, which permits unrestricted use, distribution, and reproduction in any medium, provided the original work is properly cited. 